(RESEARCH ARTICLE)

\title{
Endoscopic correlation of clinical presentation of gastroesophageal reflux disease among patients referred for gastroscopy in a tertiary hospital
}

Maiyaki Abubakar Sadiq 1, *, Yakubu Abdulmumini 1, Aminu Muhammad Sakajiki 1, Umar Hayatu 1, Balarabe Salisu Abdullahi ${ }^{1}$, Bamaiyi Adamu Jibril ${ }^{2}$, Abdullahi Ibrahim Augie ${ }^{1}$ and Usman Muawiyya Zagga ${ }^{1}$

${ }^{1}$ Department of Internal Medicine, Usmanu Danfodiyo University Teaching Hospital, Sokoto, Nigeria.

2 Department of Physiology, Usmanu Danfodiyo University, Sokoto, Nigeria.

Publication history: Received on 24 April 2020; revised on 04 May 2020; accepted on 06 May 2020

Article DOI: https://doi.org/10.30574/wjarr.2020.6.2.0124

\begin{abstract}
Gastroesophageal reflux disease (GERD) is a leading indication for gastroscopy and a common cause of serious complications among patients with dyspeptic symptoms. Ethnic variability, gender and geographical locations are some of the factors that determine severity index and complications of GERD. Upper gastrointestinal endoscopy is a reliable method used in confirming clinical suspicion of GERD. This study aimed to determine the endoscopic correlation of clinical presentations and frequency of complications among patients with clinical diagnosis of GERD referred for

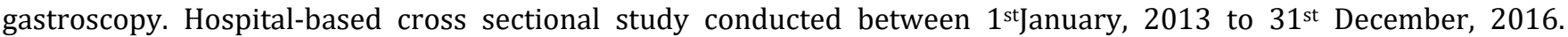
Sociodemographic characteristics and clinical diagnosis of GERD were evaluated alongside endoscopic findings. Endoscopic findings of oesophagitis, strictures, Barrett's oesophagus or oesophageal adenocarcinoma were classified as endoscopy positive while those with symptoms but with normal endoscopic finding were classified as endoscopy negative or Non-erosive reflux Disease. One thousand, five hundred and ninety seven patients were referred for gastroscopy within the study period of which 226 were GERD (14.2\%) using the self-administered questionnaire. One hundred and seven (47.3\%) were males, with M: F ratio of 1:1.1. Mean age 38.5, SD \pm 13.1 , and range of 15-75 years. The peak age occurred within the fourth decade of life (32.7\%). One hundred and seventy seven (78.3\%) were endoscopy positive, while 49 (21.7\%) were endoscopy negative GERD. Los Angeles grade B was the highest prevalence $41.2 \%$. GERD is not uncommon in our study and younger age groups are particularly more affected. Erosive esophagitis is the commonest complication encountered.
\end{abstract}

Keywords: Endoscopic; correlation clinical; Gastroesophageal reflux disease; gastroscopy

\section{Introduction}

Gastroesophageal reflux disease (GERD) is a common chronic digestive disorder in which the reflux of gastric contents into the lower oesophagus and mouth occurs due to incompetent lower esophageal sphincter (LES) associated with myriad of symptoms and/or complications [1]. The etiology of GERD is multifactorial as both environmental and genetic factors play different roles. Hiatus hernia $(\mathrm{HH})$ has been considered to be one of the pathophysiologic mechanisms that contribute to the development of GERD, promoting refluxate access and impaired acid clearance. GERD is a common disease with significant impact on quality of life [1]. Epigastric pain and/or discomfort (Heartburn) due to acid regurgitation are the common symptoms of GERD [1,2]. Characteristically, patients complain of a burning feeling in the retrosternal area, rising into the chest and radiating toward the neck, throat and occasionally the back. The symptoms are associated with meals commonly postprandially, particularly after a large fatty meal or the ingestion of spicy foods, citrus products, fats, chocolates or alcohol. Change in posture, like assumption of the supine position and bending forwards may exacerbate heartburn in GERD. Other less common symptoms include dysphagia, non-cardiac chest pain, water brash, odynophagia, burping, laryngitis, and asthma-like symptoms [1-3].

\footnotetext{
${ }^{*}$ Corresponding author: Maiyaki Abubakar Sadiq
} 
Reflux esophagitis, hemorrhage, stricture, Barrett's esophagus and esophageal adenocarcinoma may occur as complications of GERD [1-3]. The presence of classical clinical features in the absence of alarm symptoms may allow for presumptive clinical diagnosis and initiation of empirical therapy. However, a confirmatory evaluation in the form of 24-hour pH monitoring is needed especially when there is evidence of alarm symptoms. 24-hour pH monitoring is currently the goal standard in the diagnosis of GERD however upper gastrointestinal endoscopy allows for direct visualization of the esophageal mucosa and create room for biopsy and histology of suspicious lesions as a key investigation of dyspepsia in general and GERD in particular [1,2]. Esophageal manometry and impedance are other relevant investigations in GERD.

The aim of this study was to determine the endoscopic correlation of clinical presentations and frequency of complications among patients with clinical diagnosis of GERD referred for gastroscopy.

\section{Material and methods}

This was a hospital-based cross sectional study conducted from $1^{\text {st }}$ January 2013 to $31^{\text {st }}$ December, 2016. Sociodemographic and clinical diagnosis of GERD were evaluated alongside their endoscopic findings. Those with endoscopic findings of oesophagitis, strictures, Barrett's oesophagus or oesophageal adenocarcinoma were classified as endoscopy positive while those with symptoms but with normal endoscopic findings were classified as endoscopy negative or Non-erosive reflux Disease.

Each consenting patient was asked to fast overnight for at least 8 hours and at endoscopy the pharynx was anaesthetized with $10 \%$ Xylocaine spray. The shaft of the endoscope was lubricated with K-Y gel and endoscopy was performed on each patient using a forward viewing fibre-optic Olympus GIFQ-140 series video gastroscope. Conscious sedation was routinely not done before the procedure except in exceptionally restive patients where intravenous midazolam was administered according to need. GERD was defined as a condition which develops when the reflux of stomach contents causes troublesome symptoms and/or complications.

The presence of hiatus hernia was endoscopically diagnosed if the distance from the esophagogastric junction to the diaphragmatic impingement was more than $2 \mathrm{~cm}$. The detection of incomplete intestinal metaplasia in the oesophagus regardless of the length of change was considered diagnostic for Barrett's esophagus. The Los-Angeles (LA) classification was used to grade EE;

LA grade A-One or more mucosal breaks not longer than $5 \mathrm{~mm}$, none of which extends between the tops of the mucosal folds.

LA grade B-One or more mucosal breaks more than $5 \mathrm{~mm}$ long, none of which extends between the tops of two mucosal folds.

LA grade C-Mucosal breaks that extend between the tops of two or more mucosal folds, but which involve less than $75 \%$ of the esophageal circumference.

LA grade D-Mucosal breaks which involve at least 75\% of the esophageal circumference.

The data was analyzed using SPSS version 20 (Chicago IL) for windows.

\section{Results}

A total of one thousand five hundred and ninety seven patients had upper GI endoscopy over the study period, of these, 226 cases of GERD were diagnosed which constituted 14.2\%. 177 (78.3\%) were erosive while 49 (21.7\%) were NERD. One hundred and seven (47.3\%) were males, and 119 (52.7\%) were females, with male to female ratio 1:1.1.Their mean age was $38.5 \pm 13.1$, and the age range of 15-75 years respectively. The peak age incidence occurred within the fourth decade (30-39 years) of life which accounted for 74 (32.7\%) followed by the third decade (20-29 years) which constituted, 50 (22.1\%). The age distribution of the study population is depicted in Table 1. 
Table 1 Distribution of demographic characteristics

\begin{tabular}{lll}
\hline Age group & No of Patients & Percent \\
\hline$<20$ & 8 & 3.5 \\
$20-29$ & 50 & 22.1 \\
$30-39$ & 74 & 32.7 \\
$40-49$ & 42 & 18.6 \\
$50-59$ & 32 & 14.2 \\
$60-69$ & 15 & 6.6 \\
$\geq 70$ & 5 & 2.2 \\
Total & 226 & 100 \\
\hline
\end{tabular}

Table 2 Shows the distribution of EE using the Los-Angeles classification; LA grade-B has the highest prevalence 93 $(41.2 \%)$.

Table 2 Distribution of Erosive Esophagitis using the Los Angeles classification

\begin{tabular}{lll}
\hline Endoscopy Finding & Frequency & Percent \\
\hline LA Grade A & 62 & 35.1 \\
LA Grade B & 93 & 52.5 \\
LA Grade C & 19 & 10.7 \\
LA Grade D & 3 & 1.7 \\
Total & 177 & 100 \\
\hline
\end{tabular}

Table 3 highlighted the comparison of endoscopic findings and gender of patients where out of 226 cases of GERD, $49.7 \%$ (88) were females, and 50\% (89) were males. There was no statistical difference between gender and the endoscopic findings of esophagitis and NERD ( $\chi^{2}=2.00$ p-value 0.157), however more females 31 (63.3\%) (31)had NERD as compared to males $18(36.7 \%)$.

Table 3 A cross-tabulation of Endoscopic findings and gender of patients

\begin{tabular}{llll}
\hline SEX & & & \\
\hline Endoscopic Finding & Female & Male & No Patients \\
Erosive Esophagitis & 88 & 89 & 177 \\
NERD & 31 & 18 & 49 \\
\hline Total & $\mathbf{1 1 9}$ & $\mathbf{1 0 7}$ & $\mathbf{2 2 6}$ \\
\hline & $\left(\chi^{2}=2.00\right.$-value 0.157$)$ &
\end{tabular}

Table 4 showed the relationship between EE/NERD, hiatus hernia and gender of patients. There was no statistical difference between the endoscopic finding of hiatus hernia, NERD and the various LA classification of EE. $\left(\chi^{2}=2.773\right.$ Pvalue=0.096).

Table 5 shows the relationship between EE, NERD, with or without hiatus hernia with relation to gender. There was statistical difference between EE and gender difference $\left(.\left(\chi^{2}=10.53\right.\right.$ P-value $\left.=0.0012\right)$, EE with hiatus hernia and gender $\left(\left(\chi^{2}=6.47 \mathrm{P}\right.\right.$-value=0.0110) NERD, hiatus hernia and gender $\left(\left(\chi^{2}=7.86 \mathrm{P}\right.\right.$-value 0.0050$)$ but not NERD with gender alone $\left(\chi^{2}=3.32\right.$ P-value $\left.=0.0684\right)$. 
Table 4 Relationship between endoscopic findings and hiatus hernia

\begin{tabular}{lllllll}
\hline Hiatus Hernia & NERD (\%) & ERD A (\%) & ERD B (\%) & ERD C (\%) & ERD D (\%) & TOTAL \\
\hline HH+ & $15(6.6)$ & $23(10.2)$ & $32(14.2)$ & $14(6.2)$ & $2(0.9)$ & $86(38.1)$ \\
HH- & $34(15)$ & $39(17.3)$ & $61(27)$ & $5(2.2)$ & $1(0.5)$ & $140(61.9)$ \\
Total & $49(21.7)$ & $62(27.4)$ & $93(41.2)$ & $19(8.4)$ & $3(1.3)$ & $226(100)$ \\
\hline \multicolumn{5}{c}{$\left(\chi^{2}=2.773\right.$ P-value $\left.=0.096\right)$}
\end{tabular}

NERD- nonerosive reflux disease; $\mathrm{HH}+$ - Presence of hiatus hernia; ERD- erosive reflux disease (LAgrades A,B,C,D); $\mathrm{HH}$ - Absence of hiatus hernia

Table 5 Relationship between endoscopic finding, hiatus hernia and gender of patients

\begin{tabular}{lllllll}
\hline Endoscopic Finding & Female & Male & Total & df & $\chi \mathbf{2}$ & $\mathbf{P}$ - value \\
\hline EE & 35 & 61 & 96 & 1 & 10.53 & 0.0012 \\
EE+HH & 53 & 28 & 81 & 1 & 6.47 & 0.0110 \\
NERD & 21 & 13 & 34 & 1 & 3.32 & 0.0684 \\
NERD + HH & 10 & 5 & 15 & 1 & 7.86 & 0.0050 \\
Total & 119 & 107 & 226 & & & \\
\hline
\end{tabular}

\section{Discussion}

GERD is a leading indication for gastroscopy especially among patients with persistent or progressive symptoms, patients with dysphagia, odynophagia, or those with involuntary weight loss. Other categories of patients that require gastroscopy include patients with evidence of gastrointestinal bleeding, anaemia or persistent vomiting. Additionally, barium study findings of a mass, stricture or ulcer and/ or screening for Barrett's oesophagus are also indications for gastroscopy.

Gastroesophageal reflux disease is a common gastrointestinal disorder with reported increase in prevalence. Prevalence of GERD differ globally and ranges between 18.1 to $27.8 \%$ in North America, 8.8\% -25.9\% in Europe, 2.5-7.8\% in East Asia, 8.7-33.1\% in the Middle East, $11.6 \%$ in Australia and 23.0\% in South America [2].

Studies in South-western Nigeria obtained a prevalence of between 9.3-36\% [3, 4 and 5] while in Kano, North-western Nigeria [6] showed a prevalence of $24.1 \%$ respectively. In this study, the prevalence was found to be $14.2 \%$ based on GERD symptoms of mainly heartburn and regurgitation lasting days, weeks, monthly and yearly. A recent nationwide population based study reported a prevalence of $7.6 \%$ in Nigeria [7] There are several potential explanations for the differences in reported prevalence rates in different studies. This is a population based and symptom based study and therefore the lower prevalence may be explained by the fact that hospital based study is targeted at high risk population. Another factor may be attributed to cultural and language differences in symptom perception and interpretation. The term "heartburn" is commonly misinterpreted to mean a background heart disease or peptic ulcer disease. GERD has been considered to be a disease of middle age and the elderly. In our study however, the greatest proportion of patients with GERD were seen in the young adults aged 30-39 and 20-29 as has been seen in other studies [8]. This may suggest that, the younger subjects are now being exposed to possibly unidentified risk factors of GERD or are there other pathophysiologic mechanisms commoner in the young which are yet to be understood.

Further studies are needed to clarify these factors especially with increasing prevalence of GERD globally and a dearth of information in sub-Saharan Africa.

The aetiology of NERD is multifactorial as both environmental and genetic factors play different roles. NERD has been found to be commoner in women than men [9].Some studies have shown that in NERD, symptom frequency and severity are significantly higher in women than in men ${ }^{10} \mathrm{Kim}$ et al reported that EE was more common in males than in females and NERD to be commoner in females [11]. Earlier studies in South-Eastern [12] and North-Western Nigeria showed NERD to be commoner in females [6]. Ajayi and colleagues in South-western Nigeria showed EE prevalence to be $27.1 \%$ [13].However in this study, there was no statistical difference between gender and the endoscopic findings of 
oesophagitis and NERD ( $\chi^{2}=2.00$ p-value 0.157$)$, however more females $31(63.3 \%)$ (31) had NERD as compared to males 18 (36.7\%). EE accounted for 78.3\% and NERD 21.7\%. Refractory GERD is an increasing prevalent condition and it has become a major challenge to clinicians .GERD may or may not respond effectively to over the counter medications which are readily available in Nigeria. However, some patients may present with persistent or progressive symptoms despite empirical medical therapy and it may be this subset of patients that were likely referred for gastroscopy, thus the pattern of referrals.

The most important GERD complications are EE, oesophageal strictures, Barrett's oesophagus and oesophageal adenocarcinoma.The Los Angeles classification which was used in this study has been shown to be reliable, with good intra-and inter-observer agreement when tested among expert endoscopist [14]. When using the system, the severity of oesophagitis has been demonstrated to correlate with the extent of oesophageal acid exposure determined by 24hour pH monitoring [14]. According to the Los Angeles classification system, Nakase and colleagues observed a higher prevalence of endoscopic mucosal changes, grades A and B rather than C and D, in their study [15]. Similarly Ahmed and colleagues in Egypt showed grade B erosive oesophagitis to be the commonest endoscopic finding amongst their GERD patients [16]. This is in agreement with our study as most of our patients had grade B GERD 93/41.2\% followed by grade A $62 / 27.4 \%$.

In general, patients tend to remain within their phenotypic presentation throughout their lifetime with very little progression or regression [17].

Several researchers have reported hiatus hernia as a dominant predictive factor and that it promotes GERD chronicity via anatomic changes [18, 19, 20, 21, 23, and 23]. Similarly a study in Kano, North-western Nigeria showed the relationship between EE and hiatus hernia to be significant $\left(\chi^{2}=10.56 \mathrm{P}\right.$-value $\left.=0.0012\right)$ [6]. Cadiot and colleagues [24] did not find $\mathrm{HH}$ to be a significant predictor of esophagitis by multivariate analysis.

In this study, there was no statistically significant difference between the endoscopic finding of hiatus hernia, NERD and the various LA classification of $\mathrm{EE}\left(\chi^{2}=2.773 \mathrm{P}\right.$-value=0.096). The reason for this may be due to the fact that hiatus hernia were merely categorized as present or absent based on an endoscopic size of $>2 \mathrm{~cm}$ in length.

Oesophageal stricture is narrowing of the lumen of the oesophagus due to inflammation and fibrosis. Stricture was not observed at endoscopy in this study. Most patients with dyspepsia are mostly misdiagnosed to have peptic ulcer disease due to lack of diagnostic facilities. Proton pump inhibitors and histamine 2-receptor blockers are over the counter medications that are easily accessible to patients. Both medications may retard the progression of inflammation and fibrosis that results in stricture of the esophageal mucosa and may therefore explain the above findings.

Barrett's oesophagus is a premalignant condition in which the squamous epithelium of the distal oesophagus is replaced by an abnormal columnar epithelium known as specialized intestinal metaplasia with characteristic goblet cells and a risk factor to oesophageal adenocarcinoma. In this study, there was no endoscopically suspicious lesion to suggest Barrett's oesophagus or mass which is in agreement with Mason and colleagues [25] in South Africa who documented only $5 \%$ of cases of Barrett's in blacks despite the ratio of blacks to whites in the city being 5:1.

A study by Wani [26] in United States of America who prospectively studied the differences in symptoms along with demographic, clinical and endoscopic findings between African and White Americans with GERD showed that symptom profiles were very similar between the two groups; however African Americans were at a much lower risk of developing Barrett's esophagus. What has remained uncontroversial is the observation that Barrett's oesophagus is uncommon in Africa and persons of African descent in North America resulting in an equally low prevalence of adenocarcinoma of the lower oesophagus [26].

\section{Conclusion}

The present study indicated that GERD may not be rare in sub-Saharan Africa as was previously thought. Esophagitis remains the commonest finding at gastroscopy; however other complications which include strictures, Barrett's oesophagus and oesophageal adenocarcinoma are still relatively uncommon in our study area despite the growing prevalence of GERD. GERD was commoner in the fourth decade of life in our cohort. There was no correlation between the presence of $\mathrm{HH}, \mathrm{EE}$ and NERD.

However, the present work is limited by the fact that twenty-four-hour pH monitoring and multichannel intraluminal impedance studies which are considered gold standard in the diagnosis of GERD could not be performed because of non-availability of the facility in the study area. 


\section{Compliance with ethical standards}

\section{Acknowledgments}

We appreciate the cooperation of the patients who agreed to participate in the study. Our thanks goes to the management of UDUTH management for the support with ideal environment to perform the study.

\section{Disclosure of conflict of interest}

All authors declare no conflict of interest.

\section{Statement of ethical approval}

The present research work was approved by ethical committee of Usmanu Danfodiyo University Teaching hospital, Sokoto with reference number UDUTH/HREC/2012/No. 123.

\section{Statement of informed consent}

Informed consent was obtained from all individual participants included in the study.

\section{References}

[1] Tack J, Mulligan C and Johnson DA. (2012). Systemic review: the burden of disruptive Gastroesophageal reflux disease on health-related quality of life. Aliment Pharmacol Ther, 35, 1257-1266.

[2] El-Serag HB, Sweet S, Winchester CC and Dent J. (2014). Update on the epidemiology of gastroeophageal reflux disease: a systemic review Gut, 63, 871-880.

[3] Jemilohun AC, Oyelade BO, Fadare JO and Amole IO. (2018). Gastroesophageal reflux disease and etiologic correlates among Nigerian adults at Ogbomoso, South-western Nigeria. Ann Ib Postgrad Med 2, 16(1), 30-36.

[4] Akere A, Adebusoye L and Afolabi BA. (2010). Association between body mass index and Gastroesophageal reflux disease in blacks Nigeria journal of Gastroenterology and Hepatology, 2, 89-94.

[5] Onyekwere C, Adeyeye 0, Ogbera A and Duro-Emmanuel F. (2010). Prevalence of Gastroesophageal reflux disease among patients with bronchial asthma. Trop Gastroenterol, 31, 195-198.

[6] Maiyaki AS, Borodo MM, Samaila AA and Yakubu A. (2018). Prevalence of gastroesophageal reflux disease among patients with dyspepsia undergoing endoscopy in a tertiary hospital in Nigeria Sahel Med J, 21, 141-145.

[7] Nwokediuko SC, Ndububa DA, Akere A, Olokoba AB, Anyanechi CC, Umar MS, Maiyaki AS, Ijoma UC, Obienu O, Adekanle $O$ and Uhunmwangho AO. (2020). Gastroesophageal Reflux Disease in Atypical African Population: A symptom based multicenter study. BMC Gastroenterology, 20(1).

[8] Yamasaki T, Hemond C, E Mohamed, Ganocy S and Fass R. (2018). The changing epidemiology of Gastroesophageal reflux disease: are patients getting younger? J of Neurogastroenterol and motility, 24(4), 559569.

[9] Asanuma K, Iijima K and Shimosegawa T. (2016). Gender difference in gastroesophageal reflux disease. World J Gastroenterol, 22, 1800-1810.

[10] Minatsuki C, Yamamichi N, Shimamoto T, Kakimoto H, Takahashi Y, Fujishiro M, Sakaguchi Y, Nakayama C, KonnoShimizu M, Matsuda R, Mochizuki S, Asada-Hirayama I, Tsuji Y, Kodashima S, Ono S, Niimi K, Mitsushima T and Koike K. (2013). Background factors of reflux esophagitis and non-erosive reflux disease: a cross-sectional study of 10,837 subjects in Japan. PLoS One, 8(7), 26.

[11] Kim N, Lee SW, Cho SI Rew JS, Moon JS, Park CG, Yang CH, Kim S, Park H, Jung HC and Chung IS. (2008). The prevalence of and risk factors for erosive esophagitis and non-erosive reflux disease: a nationwide multicenter prospective study in Korea. Aliment Pharmacol Ther, 27, 173-85.

[12] Nwokediuko SC,Ijoma U, Obienu 0 and Agunyenwa C. (2008). Gastroesophageal reflux disease:a clinical and endoscopic study of Nigerian patients.Internet Journal of Gastroenterology, 8, 5-10.

[13] Ajayi AO, Solomon OA and Adegun PT. (2013). Prevalence of Gastroesophageal reflux disease in Ado-Ekiti, Nigeria. Journal of Gastroenterology and Hepatology, 5(2), 79-84. 
[14] Kahrilas PJ and Pandolfino JE. (2005). Review article: oesophageal pH monitoring technologies, interpretation and correlation with clinical outcomes. Aliment Pharmacol Ther, 22(Suppl 3), 2-9.

[15] Nakase H, Itani T, Mimura J, Kawasaki T, Komori H, Tomioka H and Chiba T. (1999). Relationship between asthma and gastroesophageal reflux: significance of endoscopic grade of reflux oesophagitis in adult asthmatics. J Gastroenterol Hepatol, 4(7), 715-722.

[16] Gado A, Ebeid B, Abdelmohsen A and Axon A. (2015). Prevalence of reflux oesophagitis among patients undergoing endoscopy. Alexandria J Med, 51(2), 89-9.

[17] Fass PO and Ofman JJ. (2002). Gastroesophageal reflux disease: should we adopt a new conceptual framework? Am J Gastroenterol, 97, 1901-1909.

[18] Avidam B, Sonnenberg A, Schnell TG and Sontag SJ. (2001). Risk factors for erosive reflux esophagitis: a case contro study. Am J Gastroenterol, 96, 41-46.

[19] Schindlbeck NE, Wiebecke B, Klauser AG, Voderholzer WA and Muller-Lissner SA. (1996). Diagnostic value of histology in non-erosive reflux Gastroesophageal reflux disease. Gut, 39, 151-154.

[20] Jones MP, Sloan SS, Rabine JC, Ebert CC, Huang CF and Kahrilas PJ. (2001). Hiatal hernia size is the dominant determinant of esophagitis presence and severity in Gastroesophageal reflux disease. Am J Gastroenterol, 96, 1711-1717.

[21] Yeom JS, Park HJ, Cho JS, Lee SI and Park IS. (1999). Reflux esophagitis and its relation to hiatal hernia. J Korean Med Sci, 14, 253-256.

[22] Sontag SJ, Schnell T, Miller TQ, Nemchausky B, Serlovsky R, O’Connell S, Chejfec G, Seidel UJ and Brand L. (1991). The importance of hiatal hernia in reflux esophagitis compared with lower esophageal sphincter pressure or smoking. J Clin Gastroenterol, 13, 628-643.

[23] Petersen H. (1995). The clinical significance of hiatal hernia. Scand J Gastroenterol, 211, 19-20.

[24] Cadiot G, Bruhat A, Rigaud D, Coste A, Vuagnat Y, Benyedder R, Vallot T, Guludec Le D and Mignon M. (1997). Multivariate analysis of pathophysiological factors in reflux esophagitis. Gut, 40, 167-74.

[25] Mason RJ and Bremner CG. (1998). The columnar-lined epithelium (Barrett's oesophagus in blac patients) S Afr J Surg, 36, 61-62.

[26] Wani SB, Rastogi A and Bansal A. (2007). Symptom profiles and endoscopic findings in African-American patients with gastroesophageal reflux disease Gastroenterology, 132, (Suppl) A-161.

\section{How to cite this article}

Maiyaki AS, Yakubu A, Aminu MS, Umar H, Balarabe SA, Bamaiyi AJ, Abdullahi IA and Usman MZ. (2020). Endoscopic correlation of clinical presentation of gastroesophageal reflux disease among patients referred for gastroscopy in a tertiary hospital. World Journal of Advanced Research and Reviews, 6(2), 37-43. 